\title{
Physical Activity in Pregnancy: Beliefs, Benefits, and Information-Seeking Practices of Pregnant Women in South Africa
}

This article was published in the following Dove Press journal: Journal of Multidisciplinary Healthcare

\author{
Uchenna Benedine Okafor (1D \\ Daniel Ter Goon (iD) ${ }^{2}$ \\ 'Department of Nursing Science, \\ University of Fort Hare, East London, \\ South Africa; ${ }^{2}$ Department of Public \\ Health, University of Fort Hare, East \\ London, South Africa
}

Background: Notwithstanding the benefits of physical activity (PA) during pregnancy, anecdotal evidence suggests ignorance, unscientific beliefs, and lack of awareness about PA among pregnant South African women.

Aim: This study examined the beliefs, perceived benefits, and sources of information on PA during pregnancy.

Methods: A cross-sectional descriptive study was employed between June and September 2019 using an interviewer-administered questionnaire with 1,082 pregnant women. These women were attending antenatal primary health-care clinics in Buffalo City, Eastern Cape, South Africa. A self-designed questionnaire solicited information on beliefs, benefits, and sources of information regarding PA during pregnancy.

Results: A majority of the participants held positive beliefs concerning PA during pregnancy. They maintained that PA was safe for mother and fetus, improved labor and delivery (93.1\%), promoted energy (89.0\%), and should be discontinued when tired (76.6\%). Most held negative convictions that PA during pregnancy increased body temperature $(64.5 \%)$ and that pregnancy was a time to rest and refrain from PA (56.5\%). Predominantl sources of information received about PA during pregnancy were television, the radio, and other media (70.2\%). Most participants were aware of the benefits of PA during pregnancy — reduction in infant weight (61.4\%), lessening of moodiness (90.4), and decreased risk of gestational diabetes mellitus (92.9\%), pregnancy-induced hypertension (92.5\%), and complications at birth (97.8\%), while common negative perceptions included musculoskeletal discomfort (82.7\%), and back pain (85.7\%). An overwhelming majority affirmed that PA improved self-image (95.7\%), sleep patterns (94.2\%), and respiratory function $(95.8 \%)$.

Conclusion: Our findings suggested that women hold positive beliefs and perceive PA as beneficial to their health and the baby; however, they received most of their information from the Internet. Most women regarded pregnancy as a period to relax and rest. Interventions to promote PA during pregnancy are needed.

Keywords: physical activity, beliefs, perceived benefits, sources of information, pregnancy

\section{Introduction}

Historically, physical activity participation in pregnant women was frowned upon and discouraged. However, scientific evidence has proven that physical activity in pregnancy is beneficial for the mother and her unborn child. Benefits include reduced risk of excessive gestational weight gain, ${ }^{1-4}$ gestational diabetes, ${ }^{1,5,6}$ and preeclampsia. $^{7-10}$ Physically active pregnant women have lower rates of preterm birth, altered fetal growth, ${ }^{11,12}$ miscarriage, ${ }^{13}$ prolonged cesarean section and
Correspondence: Uchenna Benedine Okafor

University of Fort Hare, East London, South Africa

Email ucheysonic@gmail.com 
postpartum recovery, ${ }^{14-16}$ and risk of injury for both mother and baby. ${ }^{2}$ These findings reflect a confirmation of the safety of prenatal physical activity and help to clarify beliefs and misconceptions held by some individuals that physical activity during pregnancy is harmful to the baby. Moreover, physical activity during pregnancy improves the sleep of the mother. ${ }^{17,18}$ Other benefits include reduced length of labor, delivery complications, ${ }^{19}$ birth weight, ${ }^{12}$ fatigue, stress, anxiety, depression, ${ }^{13,20-23}$ and low-back pain. ${ }^{7,9,24}$ A recent study showed that physical activity during pregnancy was associated with improved breastfeeding outcomes. ${ }^{25}$ With these benefits, the guidelines recommend that pregnant women engage in physical activity. ${ }^{26}$ However, low prenatal physical activity is shaped by multiple factors at play insociocultural, economic, political, and environmental contexts in different settings across countries.

The literature abounds with the manifold benefits of prenatal physical activity for maternal and fetal health; ${ }^{27}$ therefore, determining beliefs about prenatal physical activity will provide useful information to inform the development of successful and appropriate intervention strategies. $^{28}$ However, beliefs and attitudes of women toward prenatal physical activity varies among cultures, ${ }^{29}$ and understanding these variations across different cultures and settings is important to tailor context-specific physical activity interventions to promote optimal physical activity participation during pregnancy. In addition, providing pregnant women with accurate and sufficient advice on the type and prescription of physical activity during pregnancy might influence their attitude in terms of initiating and engaging in physical activity. Uunderstanding where women get advice on physical activity during pregnancy and what advice they act upon is necessary for improving the health-care support already in place. ${ }^{30}$ Physical activity plays a significant role in maternal health; therefore, creating awareness of its benefits and contraindications may change women's negative attitudes toward physical activity and promote it for better maternal outcomes, which might decrease the burden of preventable pregnancy-related conditions on the health-care system. ${ }^{31}$

There is a dearth of research on physical activity in pregnancy in South Africa. Specifically, research seeking to understand beliefs about, sources of information, and perceived benefits of physical activity during pregnancy is lacking. The only known study involved a small, homogeneous sample of urbanized black South African women and did not represent other races, cultures, or communities. $^{32}$ Therefore, the present study aimed to examine the beliefs about and perceived benefits of physical activity during pregnancy, and to identify sources of information on physical activity among a diverse pregnant South Africanwomen attending antenatal health facilities in Eastern Cape province.

\section{Methods}

\section{Design and Setting}

This cross-sectional study was conducted on 1,082 pregnant women from June to September 2019 at 12 randomly selected primary health-care clinics offering antenatal health services in Buffalo City, Eastern Cape province. Buffalo City is one of four municipalities within Eastern Cape, and is located on the east coast of the Province. It has a population of 884,000 , with women constituting around $48.01 \%$. Eastern Cape is economically one of the poorest provinces in South Africa. ${ }^{33}$ The municipality has two provincial hospitals two district hospitals, five community health centers, 72 primary-health clinics, and 12 mobile health services. ${ }^{33}$ Antenatal health-care services are free for all women attending the community health centers and primary-health clinics. On average, these health centers register five to six newly pregnant women per day. An estimated 17,000 pregnant women visit the 12 selected primary-health clinics for antenatal services annually. The 72 primary-health centers were numbered, and using random number-generator software 12 centers were selected.

\section{Sample-Size Determination and Sampling Procedure}

Sarmah et $\mathrm{al}^{34}$ formule was applied to calculate the sample size at a confidence level of $95 \% \pm 3 \%$, and with physical activity or exercise participation during pregnancy of $50 \%$ $(p=0.5) \mathrm{s}$ :

$$
\begin{aligned}
& p=0.5, \text { hence } q=1-0.5=0.5 ; e=0.03 \text {, and } z=1.96 \text {, } \\
& \text { so } n_{0}=\frac{(1.96)^{2}(0.5)(0.5)}{(0.3)^{2}}=1067=1067
\end{aligned}
$$

At a $10 \%$ nonresponse rate, the final sample size was 1,215 women, accounting for possible attrition and data loss.

Participants were convenience-selected by the principal investigator during antenatal visits. Eligibility criteria were age: 18 years or older, receiving antenatal care, single pregnancy (not multiple), and ability to read or understand Xhosa, Afrikaans, or English. Conversely, women with 
disabilities or preexisting health conditions limiting prenatal activity at the time of recruitment or with one or more contraindications for physical activity (severe chest pain, persistent shortness of breath, and vaginal bleeding) were excluded. Participants were interviewed in a quiet room provided by the facility manager.

\section{Data Collection}

Data were collected using an interview-administered questionnaire between July and October 2019. The questionnaire was interview-administered in order to maximize accuracy and ensure completeness of information from the participants. It focused on socio-demographic, obstetric, maternal, and lifestyle characteristics. Demographic variables comprised age $(<19,19-34,>34$ years $)$, residence (rural, semiurban, urban), ethnicity (black, colored), marital status (married, single, cohabiting), education (primary, secondary, tertiary), employment status (unemployed, employed), religion (Christian, other), and family support (adequate, moderate, none). Behavioral and lifestyle characteristics included current exposure to alcohol and smoking. Women were categorized as smokers if smoking cigarettes during pregnancy and nonsmokers if not smoking. Women who reported any alcohol use during pregnancy were classified as drinkers, while 'nondrinkers' were women reporting no drinking. Information on parity (nulliparous, primiparous, multiparous), mode of delivery (vaginal, cesarean section or both), and pregravid bodymass index (low $<19.8$, normal $(19.8-<26$ ), overweight $26-<30$ ) was obtained from antenatal medical records. In addition, we solicited information on antepartum hemorrhage in their first trimester, perceived health in pregnancy (very good, good, bad) presence of any chronic illness, prenatal physical activity advice received from health professionals, and whether they engaged in physical activity before pregnancy.

Outcome measures were beliefs, benefits, and information-seeking practices of pregnant women about physical activity and exercise during the pregnancy questionnaire, which was developed based on information in the literature. ${ }^{35-37}$ Women completed the questionnaire while waiting for their antenatal appointments. The questionnaire contained 19 items on beliefs on a five-point Likert scale ranging from 1 (strongly disagree) to 5 (strongly agree), and the questionnaire onperceived benefits of physical activity during pregnancy contained 17 item statements on a 5-point Likert scale ranging from 1 (strongly disagree) to 4 (strongly agree). Finally, participants indicated sources of information (friends, family, other women, health professionals, social media, television, radio, books, newspapers, magazines, other) on physical activity during pregnancy with the response options "often, rarely, and never".

The content and face validity of the questionnaire was ascertained by two experts in the field and revisions made. In addition, it was pilot-tested with 20 pregnant women to establish whether the questions seemed clear and concise to the participants. Samples from the pilot study were excluded from the main study. Additional revisions pertaining to wording were made to ensure clarity. The estimated Cronbach's $\alpha$ was 0.69 .

\section{Data Analysis}

Data were analyzed using descriptive statistics, ie, frequency and percentage. Statistical analysis was conducted using SPSS 23.0 for Windows.

\section{Results}

Participants' mean age was $27.0 \pm 6.2$ years. A vast majority of women were aged $19-34$ years $(75.1 \%)$, living in an urban location (48.3\%), black (86.4\%), had never married (66.3\%), with secondary education (74.2\%), unemployed (67.7\%), Christian (89.1\%), and had family support (77.4\%). Nulliparous women comprised $47.8 \%$ of participants, 93.6\% had had antepartum hemorrhage, $42 . \%$ vaginal, and $49.7 \%$ both vaginal and Cesarean section deliveries, perceived their health as good (59.3\%), had no chronic illness (93.5\%), did not smoke $(91.7 \%)$ or drink alcohol (86.4\%), and had normal pregravid bodymass index (84.0\%). A majority had not received any physical activity advice or counseling (65.1\%) and never participated in physical activity (69.6\%) during pregnancy (Table 1).

\section{Physical Activity and Exercise Beliefs}

Key beliefs of participants concerning physical activity during pregnancy are presented in Table 2. These were mostly positive. For instance, $77.6 \%$ of participants disagreed and strongly disagreed with the statement that physical activity was not safe for the mother or fetus, reduced placental circulation (66.7\%), could lead to abortion or miscarriage, preterm birth, and intrauterine growth retardation $(75.1 \%)$, and was harmful $(64.9 \%)$. A majority affirmed pregnant women should not exercise while lying on their back $(75.5 \%)$ and held the view that standing in one place for a long time without 
Table I Sociodemographic, Obstetric, and Lifestyle Characteristics of Participants

\begin{tabular}{|c|c|}
\hline & n (\%) \\
\hline \multicolumn{2}{|l|}{ Age (years) } \\
\hline$<19$ & $118(10.9)$ \\
\hline $19-34$ & $812(75.1)$ \\
\hline$>34$ & $152(14.0)$ \\
\hline \multicolumn{2}{|l|}{ Residence } \\
\hline Rural & $118(10.9)$ \\
\hline Semiurban & $44 \mid(40.8)$ \\
\hline Urban & $523(48.3)$ \\
\hline \multicolumn{2}{|l|}{ Ethnicity } \\
\hline Black & $935(86.4)$ \\
\hline Colored & $147(13.6)$ \\
\hline \multicolumn{2}{|l|}{ Marital status } \\
\hline Married & $236(21.8)$ \\
\hline Never married & $717(66.3)$ \\
\hline Cohabiting & $129(11.9)$ \\
\hline \multicolumn{2}{|l|}{ Education } \\
\hline Primary & $84(7.8)$ \\
\hline Secondary & $803(74.2)$ \\
\hline Tertiary & $195(18.0)$ \\
\hline \multicolumn{2}{|l|}{ Employment } \\
\hline Unemployed & $733(67.7)$ \\
\hline Employed & $349(32.3)$ \\
\hline \multicolumn{2}{|l|}{ Religion } \\
\hline Christian & $964(89.1)$ \\
\hline Other & $118(10.9)$ \\
\hline \multicolumn{2}{|l|}{ Family support } \\
\hline Adequate & $837(77.4)$ \\
\hline Moderate & $223(20.6)$ \\
\hline None & $22(2.0)$ \\
\hline \multicolumn{2}{|l|}{ Parity } \\
\hline Nulliparous & $517(47.8)$ \\
\hline Primiparous & $322(29.8)$ \\
\hline Multiparous & $243(22.4)$ \\
\hline \multicolumn{2}{|l|}{ Delivery mode } \\
\hline Vaginal & $457(42.2)$ \\
\hline Cesarean section & $87(8.1)$ \\
\hline Both & $538(49.7)$ \\
\hline \multicolumn{2}{|c|}{ Antepartum hemorrhage } \\
\hline Yes & $69(6.4)$ \\
\hline No & $1013(93.6)$ \\
\hline \multicolumn{2}{|l|}{ Perceived health } \\
\hline Very good & $440(40.7)$ \\
\hline Good & $631(58.3)$ \\
\hline Bad & II (I.0) \\
\hline
\end{tabular}

(Continued)
Table I (Continued).

\begin{tabular}{|c|c|}
\hline & n (\%) \\
\hline \multicolumn{2}{|l|}{ Smoking status } \\
\hline Yes & $90(8.3)$ \\
\hline No & $992(91.7)$ \\
\hline \multicolumn{2}{|l|}{ Alcohol use } \\
\hline Yes & $147(13.6)$ \\
\hline No & $935(86.4)$ \\
\hline \multicolumn{2}{|l|}{ Pregravid body-mass index $\left(\mathrm{kg} / \mathrm{m}^{2}\right)$} \\
\hline Underweight $(<18.5)$ & $22(2.0)$ \\
\hline Normal weight (18.5-24.9) & $917(84.8)$ \\
\hline Overweight (25.0-29.9) & $143(13.2)$ \\
\hline \multicolumn{2}{|l|}{ Planned pregnancy } \\
\hline Yes & $35 I(32.4)$ \\
\hline No & $731(67.6)$ \\
\hline \multicolumn{2}{|l|}{ Physical activity advice } \\
\hline Yes & $382(35.3)$ \\
\hline No & $700(64.7)$ \\
\hline \multicolumn{2}{|l|}{ Physical activity before pregnancy } \\
\hline Yes & $378(34.9)$ \\
\hline No & $704(65.1)$ \\
\hline \multicolumn{2}{|l|}{ Physical activity timing } \\
\hline First trimester & $188(17.4)$ \\
\hline Second trimester & $114(10.5)$ \\
\hline Third trimester & $27(2.5)$ \\
\hline Never & $753(69.6)$ \\
\hline
\end{tabular}

moving was not advisable in pregnancy (94.0\%). Most pregnant women had a negative conviction that participation in physical activity during pregnancy increased body temperature $(64.5 \%)$. Most participants did not support the notion that physical activity increased the risk of maternal musculoskeletal injuries and diversion of maternal oxygen and nutrients to skeletal muscle, rather than to the fetus $(51.6 \%)$. However, a majority held positive beliefs: regular physical activity during pregnancy is permissible (87.4\%), women not previously engaging in exercise can commence exercise during pregnancy $(81.0 \%)$, and exercise improves labor and delivery (93.1\%) and the health of the baby (93.1\%) and promotes energy $(89.0 \%)$. Interestingly, a majority held the positive view that it is not recommended to continue exercising when tired $(76.6 \%)$, endorsed exercise at least three times per week (85\%) However, $56.5 \%$ indicated that pregnancy was a time to just rest and refrain from physical activity. 
Table 2 Beliefs About Physical Activity and Exercise During Pregnancy

\begin{tabular}{|c|c|c|c|c|c|}
\hline & \multicolumn{5}{|c|}{ Responses } \\
\hline & SA & $\mathbf{A}$ & $\mathbf{N}$ & D & SD \\
\hline & n (\%) & n (\%) & n (\%) & n (\%) & n (\%) \\
\hline Not safe for mother or fetus & $89(8.2)$ & $84(7.8)$ & $69(6.4)$ & $456(42.1)$ & $384(35.5)$ \\
\hline Reduces placental circulation & $31(2.9)$ & $126(11.6)$ & $203(18.8)$ & $429(39.6)$ & $293(27.1)$ \\
\hline Leads to abortion or miscarriage, preterm birth, intrauterine growth retardation & $49(4.5)$ & $248(22.9)$ & $81(7.5)$ & $490(45.3)$ & $214(29.8)$ \\
\hline Regular exercise during pregnancy is harmful & $39(3.6)$ & $267(24.7)$ & $74(6.8)$ & $429(39.7)$ & $273(25.2)$ \\
\hline No exercise while lying on back during pregnancy & $89(8.2)$ & $728(67.3)$ & $142(13.1)$ & $97(9.0)$ & $26(2.4)$ \\
\hline Avoid long periods of standing in one place without moving while pregnant & $459(42.4)$ & $558(51.6)$ & $35(3.2)$ & $24(2.2)$ & $6(0.6)$ \\
\hline Physical activity increases body temperature & $92(8.5)$ & $606(56.0)$ & $153(14.1)$ & $187(17.3)$ & $0(0)$ \\
\hline $\begin{array}{l}\text { Physical activity increases the risk of maternal musculoskeletal injuries and } \\
\text { diversion of maternal oxygen and nutrients to skeletal muscle, rather than to } \\
\text { the fetus }\end{array}$ & $81(7.5)$ & $279(25.8)$ & $164(15.1)$ & $46 I(42.6)$ & $97(9.0)$ \\
\hline Women can continue regular exercise during pregnancy & $155(14.3)$ & $791(73.1)$ & $26(2.4)$ & $94(8.7)$ & $16(1.5)$ \\
\hline $\begin{array}{l}\text { Women who have never exercised can begin an exercise program during } \\
\text { pregnancy }\end{array}$ & $176(16.3)$ & $700(64.7)$ & $95(8.8)$ & $88(8.1)$ & $23(2.1)$ \\
\hline Improves a woman's labor and delivery & $214(19.8)$ & $793(73.3)$ & $32(3.0)$ & $38(3.5)$ & $5(0.4)$ \\
\hline Improves the health of the baby & $215(19.9)$ & $792(73.2)$ & $44(4.1)$ & $26(2.4)$ & $5(0.4)$ \\
\hline Feel more energetic & $216(20.0)$ & $747(69.0)$ & $36(3.3)$ & $69(6.4)$ & $14(1.3)$ \\
\hline A pregnant woman can continue to exercise even if she becomes tired & $45(4.2)$ & $180(16.6)$ & $28(2.6)$ & $455(42.0)$ & $374(34.6)$ \\
\hline $\begin{array}{l}\text { During pregnancy, regular exercise at least three times per week is better than } \\
\text { activity done irregularly or less often }\end{array}$ & $204(18.8)$ & $716(66.2)$ & 81 (7.5) & $64(5.9)$ & $17(1.6)$ \\
\hline Pregnancy is a time to rest & $210(19.4)$ & $401(37.1)$ & $13(1.2)$ & $317(29.3)$ & $|4|(\mid 3.0)$ \\
\hline
\end{tabular}

Abbreviations: SA, strongly agree; $A$, agree; $\mathrm{N}$, neutral; D, disagree; SD, strongly disagree.

\section{Perceived Benefits}

Figure 1 presents the perceived benefits of physical activity during pregnancy. A majority of participants maintained that physical activity was beneficial in improving cardiovascular function $(86.2 \%)$ and reduction in infant weight (61.4\%), musculoskeletal discomfort (82.7\%), back pain $(85.7 \%)$, and incidence of muscle cramps and edema in lower limbs (91.3\%). In addition, most indicated physical activity in pregnancy improved labor and delivery (96.9\%), health of the baby (96.9\%) and the mother (98.2\%), and mood (90.4\%). A majority affirmed that physical activity during pregnancy decreased the risk of gestational diabetes mellitus (92.9\%), pregnancy-induced hypertension (92.5\%), and complications at birth (97.8\%). An overwhelming majority affirmed that physical activity improved self-image (95.7\%), sleep patterns (94.2\%), and respiratory function $(95.8 \%)$.

\section{Information Sources}

Sources of information and advice received by the participants about physical activity are shown in Figure 2: friends $(27.0 \%)$, family $(45.3 \%)$, other women $(18.2 \%)$, health-care professionals (47.2\%), and books, newspapers and magazines (49.1\%). The predominant source of information they received about physical activity in pregnancy was from television, the radio, and other media $(70.2 \%)$.

\section{Discussion}

To our knowledge, this is the first study exploring the beliefs, sources of information, and perceived benefits of 


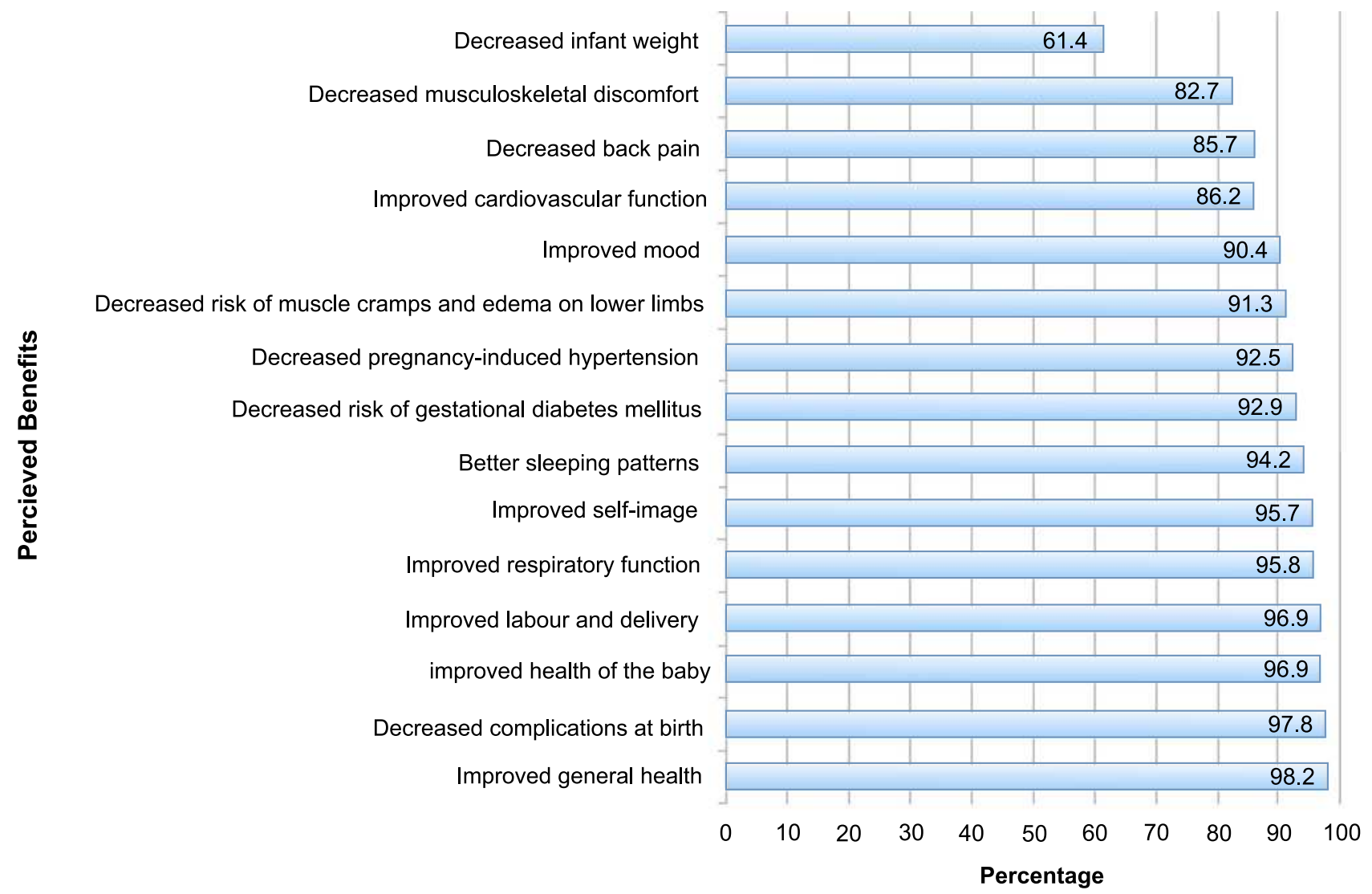

Figure I Perceived benefits of physical activity during pregnancy.

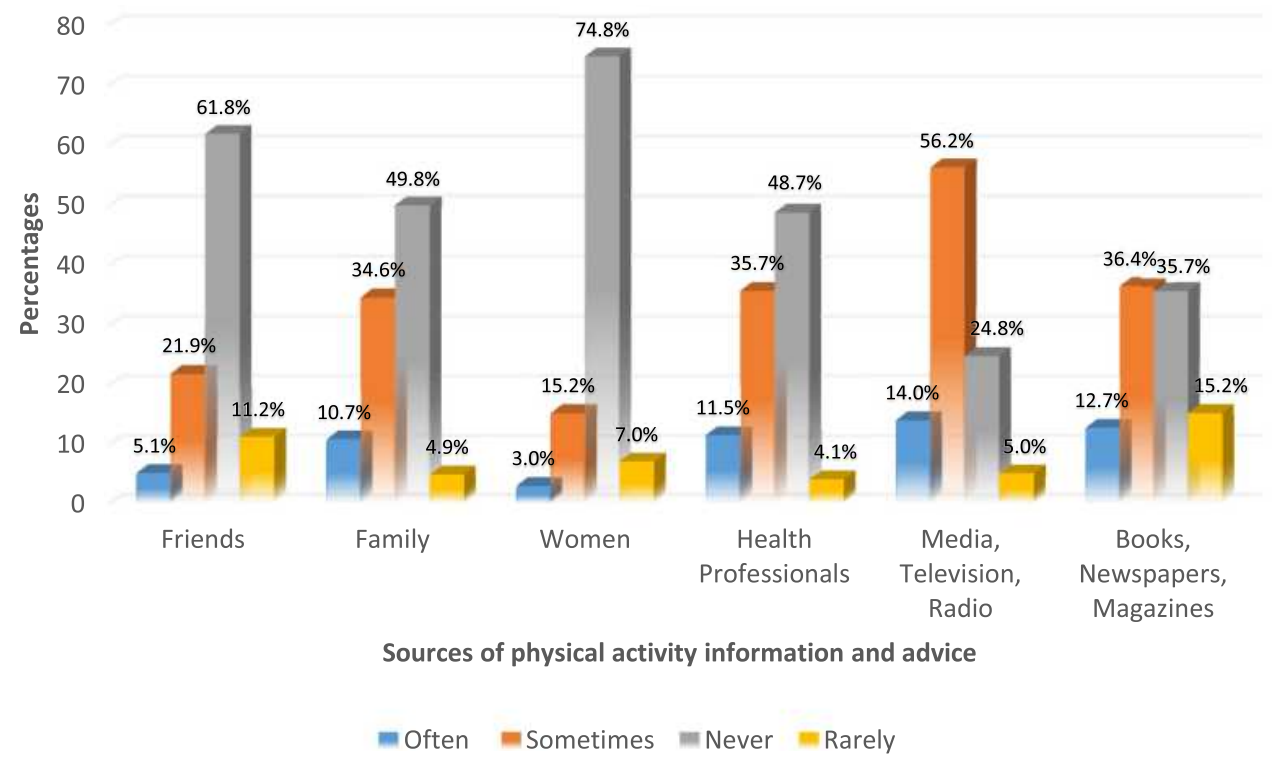

Figure 2 Sources of information on physical activity.

physical activity among pregnant women in a low-income and diverse sample in Eastern Cape, South Africa. Physical activity plays an important role in maternal health; therefore, understanding beliefs, where women get advice, and perceived benefits of physical activity during pregnancy may help in designing educational interventions to encourage, promote, and sustain physical activity among pregnant women. Our study revealed 
general positive beliefs about physical activity among the women. Notably, they affirmed the physiological and psychological benefits of being physically active, alongside helping to relieve anxiety or improve mood and consequently correct negative perceptions of prenatal physical activity risk during pregnancy. An overwhelming majority held the positive beliefs that regular exercise during pregnancy was permissible (87.4\%), women not previously engaging in exercise could commence exercise during pregnancy $(81.0 \%)$, and that it improved labor and delivery $(93.1 \%)$ and the health of the baby $(93.1 \%)$, and promoted energy $(89.0 \%)$, and endorsed regular exercise at least three times weekly (85\%). These positive beliefs about physical activity align with a previous study in South Africa ${ }^{32}$ and others elsewhere, in which pregnant women have expressed the benefits of prenatal physical activity, ${ }^{28,30,38,39}$ which serves as an enabling influencer to engage in prenatal activity during pregnancy. If women are informed about the importance of physical activity during pregnancy, this will invariably challenge their traditional beliefs about pregnancy-related risk. Therefore, interventions to improve perceptions of women regarding the benefits of prenatal physical activity are crucial to promote such activity.

In contrast, $56.5 \%$ of the women in this study indicated that pregnancy was a time to rest and refrain from physical activity, which contradicts international guidelines on exercise in pregnancy. Thissuggests somewhat of an element of negative belief and ignorance versus positive beliefs, which is difficult to explain. Suffice it to say that the women might have had prior positive beliefs about physical activity, but seemingly did not have adequate knowledge about the benefits of physical activity during pregnancy. Studies have reported women's lack of knowledge about the benefits of physical activity during pregnancy. ${ }^{40,41}$ Perhaps the belief that pregnancy is a "rest time" among women in our study could be shaped by social or cultural underpinnings, which is in itself speculative here. Further studies should endeavor to elucidate on social and cultural elements shaping physical activity beliefs with qualitative research.

Nevertheless, as with other studies, pregnant women have expressed the belief that pregnancy is a period to rest. For example, Guelfi et $\mathrm{al}^{29}$ compared beliefs about exercise during pregnancy between pregnant Chinese and Australian women, and reported that the Chinese women attached more importance to the sedentary behaviors of sleeping and resting/relaxing than exercise and having an active lifestyle. Conversely, the Australian women regarded resting/relaxing to be less important than exercise and having an active lifestyle. Other studies have reported women regarding resting and recuperation during pregnancy a priority. ${ }^{32,42}$ Interventions to help disabuse women of the erroneous belief that pregnancy presents a time for resting rather than physical activity practice is needed. A potential strategy to promote awareness about prenatal physical activity is through technology-assisted programs. The MomConnect technology initiative in South Africa is a classic example to use. MomConnect is a program to provide maternal health-related information for pregnant women that can be used to share knowledge of prenatal physical activity benefits to women. Applying technology-assisted (mobile health) programs confers several benefits to the target population, as health information can be delivered at any place and time, is participatory, uses real-life settings, and is accessible to a vast population, regardless of their socioeconomic status or geographic setting. ${ }^{43,44}$ In a systematic review, the utilization of mobile phone-based health-behavior interventions in pregnancy correlated with positive beliefs, behaviors, and health outcomes. ${ }^{45}$

Interestingly, our findings revealed that a majority of the women knew the benefits of physical activity during pregnancy. However, knowledge about a health phenomenon does not necessarily translate into positive practice. It remains to be seen whether the knowledge is put to use or not. In this regard, pregnant women need encouragement, guidance, and advice to initiate and maintain a healthier lifestyle behavior. Evidence-based physical activity advice should come from health-care providers, who serve as intermediary between the pregnant woman and her child during pregnancy. Research has shown that maternal advice from health-care providers is more desirable and motivating to women to exercise during pregnancy. ${ }^{32,46}$ As in other studies elsewhere, women indicated awareness of the physiological and psychological ${ }^{28,30,39,47}$ benefits of physical activity. Even with such awareness, studies have reported low physical activity among women in both developed $^{48-51}$ and developing nations, ${ }^{52-55}$ with few women meeting the 150-minute/week exercise recommendation. One salient feature of this finding is that knowledge of the benefits of physical activity during pregnancy signals an important message to health-care providers that it is inconsequential directing effort and resources to increasing current levels of education. ${ }^{56}$ Instead, it would be appropriate and prudent to apply the theory of planned 
behavior, ${ }^{57}$ which incorporates other variables, such as barriers, enablers, and social factors, as influencers of intention and subsequent behavior. ${ }^{57,58}$ In this context, factoring in the aspects of social support, time efficiency, fun, and enjoyment as interventional efforts is important to ignite desirable behavioral change. ${ }^{59}$ Initiating such action may prove more effective in improving pregnant women's participation in physical activity than knowledge or education strategies alone. ${ }^{56}$

Our findings revealed that a majority of the women received information about physical activity in pregnancy from social media, television, and radio (70.2\%), and books, newspapers, and magazines (49.1\%). Similarly, other studies have reported that apart from health professionals, books, the Internet, and social media form a substantial proportion of pregnancy-related sources of information for women. ${ }^{60-62}$ In Mercado et al's ${ }^{63}$ study, pregnant women reported receiving prenatal physical activity information mostly from books and the Internet. A majority of the women (65.1\%) in the present study indicated receiving no physical activity advice from the midwives responsible for their antenatal care at clinics. This is similar to other studies ${ }^{30,63-66}$ and an earlier study in South Africa ${ }^{67}$ Similarly, another study reported that only $19 \%$ of South African medical practitioners provided information on physical activity during prenatal visits. ${ }^{68}$ Where advice was provided, it was conflicting and misleading, and did not extend beyond telling them "to walk", ${ }^{69}$ or the advice is minimal and ineffective. ${ }^{70}$ Studies have shown that health-care professionals lack the confidence and knowledge to deliver physical activity advice during routine care. ${ }^{66}$ Bearing this in mind, it is unsurprising to discover the disconnect that exists between the evidence for the benefits of physical activity and corresponding behaviors during pregnancy, largely because of a lack of effective information on physical activity from the health-care providers.

Antenatal health-care professionals, primarily midwives, are the key sources of information for pregnant women in South Africa. They have regular contact with pregnant women who routinely visit antenatal health clinics for checkups. It may be possible that the lack of information about physical activity from the midwives would definitely propel the women to resort to seeking information or advice on physical activity from friends, family, magazines, and largely the Internet. There is a potential risk if pregnant women are not receiving evidence-based physical activity advice from health-care professionals, but predominantly from the Internet. Online information cannot necessarily be trusted and can be misleading. Some studies have shown that Internetbased physical activity advice often lacked accuracy and was in most instances misleading. ${ }^{71-74}$ This suggests the need for training of midwives and other health professionals to deliver evidence-based physical activity advice during pregnancy. Such training should start at the undergraduate level, and continue after graduation with professional practice training. With training, time, and resource allocation to physical activity as part of maternal healthcare, the desired change in physical activity behavior and practice might occur. Physical activity during pregnancy should be viewed as a holistic and integrative approach to maternal care. A synergistic working attitude among health professionals saddled with the responsibility of advising pregnant women is imperative to support physical activity during and beyond pregnancy.

\section{Implications for Practice and Research}

The finding that pregnant women perceived physical activity as beneficial to their health and the baby's, received most of their physical activity information through Internet sources, rather than from midwives, who maintain face-toface contact with women during antenatal health-care sessions, highlights two scenarios. Firstly, there is a need to design interventions that will create prenatal awareness among women, and secondly a needto assess the quality of Internet-based physical activity advice, in order to educate pregnant women accordingly to avoid misinformation. As can be seen from this present study, an overwhelming majority of the women had positive belief and understood the benefits of physical activity, yet considered pregnancy a period of no physical activity, but to rest. A recent study reported that women viewed pregnancy as a time to relax and received encouragement from families and peers to avoid physical activity. ${ }^{70}$ This suggests that more interventions are needed to change the physical activity behavior of women during pregnancy. Providing adequate training to midwives and other health professionals on physical activity in pregnancy could be a powerful intervention in promoting the uptake of physical activity among pregnant women, as these health professionals would in turn provide accurate advice and information about physical activity during pregnancy. Counseling has a strong influence in changing women's health beliefs and behaviors. ${ }^{75,76}$ The findings of this study underscore the importance of designing interventions to improve 
prenatal physical activity in an understudied, low-income, and diverse sample of pregnant women in the Eastern Cape, and further highlight the need for future study involving pregnant women seeking antenatal health care in the private health sector.

\section{Limitations}

One obvious limitation of the study was the use of a selfreported questionnaire to solicit information from participants, where the possibility of response bias cannot be ruled out. In addition, the study was limited to pregnant women attending public primary-health clinics; therefore, the findings cannot be generalized to women attending private health facilities. Future studies should endeavor to include women attending private health facilities. Notwithstanding, this study provides insight into the beliefs, perceived benefits, and sources of physical activity information during pregnancy among a diverse and large sample of pregnant women in an understudied, lowresource setting. The data might inform interventions on changing perceptions about physical activity and the need to provide health facility-based physical activity advice and counseling for pregnant women during antenatal visits.

\section{Conclusion}

Notwithstanding the fact that a majority of the women did not participate in physical activity before or during pregnancy, they had positive perceptions about the advantages of prenatal physical activity for their health and the baby's; however, most regarded pregnancy as a period to relax and rest. The predominant source of prenatal physical activity advice was gleaned from the Internet, which can be potentially misleading or contradictory to evidence-based physical activity practice. Interventions targeted at promoting prenatal physical activity, specifically to address erroneous beliefs about prenatal physical activity, are warranted. Given the scarcity of information on this topic in lowincome and diverse samples, our data serve as a baseline for future comparative studies on the matter.

\section{Ethicals}

The study was conducted according to the Declaration of Helsinki. Informed consent was obtained from participants before data collection. The purpose, nature, and procedures of the study were explained to the participants before they signed the informed-consent form to participate in the study. The Health Research Ethics Committee of the University of Fort Hare approved the study (\#2019=06=009=OkaforUB).

\section{Acknowledgment}

This work is supported by Govan Mbeki Research and Development Center, University of Fort Hare, South Africa.

\section{Author Contributions}

All authors made a significant contribution to the work reported, whether in conception, study design, execution, acquisition of data, analysis and interpretation, or in all these areas, took part in drafting, revising, or critically reviewing the article, gave final approval to the version to be published, agreed on the journal to which the article has been submitted, and agree to be accountable for all aspects of the work.

\section{Funding}

None.

\section{Disclosure}

The authors declare no conflicts of interest for this work.

\section{References}

1. da Silva SG, Ricardo LI, Evenson KR, Hallal PC. Leisure time physical activity in pregnancy and maternal-child health: a systematic review and meta-analysis of randomized controlled trials and cohort studies. Sports Med. 2017;47(2):295-317.

2. Whitaker KM, Wilcox S, Liu J, Blair SN, Pate RR. Pregnant women's perceptions of weight gain, physical activity, and nutrition using Theory of Planned Behavior constructs. J Behav Med. 2016;39 (1):41-54.

3. Dipietro L, Evenson KR, Bloodgood B, et al. Benefits of physical activity during pregnancy and postpartum: an umbrella review. Med Sci Sports Exerc. 2019;51(6):1292-1302.

4. Ruchat SM, Mottola MF, Skow RJ, et al. Effectiveness of exercise interventions in the prevention of excessive gestational weight gain and postpartum weight retention: a systematic review and meta-analysis. Br J Sports Med. 2018;52(21):1347-1356. doi:10.1136/bjsports2018-099399

5. Harrison AL, Shields N, Taylor NF, Frawley HC. Exercise improves glycaemic control in women diagnosed with gestational diabetes mellitus: a systematic review. $J$ Physiother. 2016;62(4):188-196. doi:10.1016/j.jphys.2016.08.003

6. Aune D, Schlesinger S, Henriksen T, et al. Physical activity and the risk of preterm birth: a systematic review and meta-analysis of epidemiological studies. BJOG Int J Obstet Gynaecol. 2017;124(12):18161826. doi:10.1111/1471-0528.14672

7. Thompson EL, Vamos CA, Daley EM. Physical activity during pregnancy and the role of theory in promoting positive behavior change: a systematic review. $J$ Sport Health Sci. 2017;6(2):198-206. doi:10.1016/j.jshs.2015.08.001

8. Catov JM, Parker CB, Gibbs BB, et al. Patterns of leisure-time physical activity across pregnancy and adverse pregnancy outcomes. Int $J$ Behav Nutr Phys Act. 2018;15:68-78. doi:10.1186/s12966-018-0701-5 
9. Puchalski S. Physical activity: utilizing guidelines to promote health among pregnant women. J Preg Reprod. 2017;1(2):1-3. doi:10.15 761/JPR.1000107

10. Davenport MH, Ruchat SM, Poitras VJ, et al. Prenatal exercise for the prevention of gestational diabetes mellitus and hypertensive disorders of pregnancy: a systematic review and meta-analysis. Br J Sports Med. 2018;52(21):1367-1375. doi:10.1136/bjsports-2018-099355

11. Vamos CA, Flory S, Sun H, et al. Do physical activity patterns across the life course impact birth outcomes? Matern Child Health J. 2015;19(8):1775-1782. doi:10.1007/s10995-015-1691-4

12. Davenport MH, Meah VL, Ruchat S, et al. Impact of prenatal exercise on neonatal and childhood outcomes: a systematic review and meta-analysis. Br J Sports Med. 2018b;52(21):1386-1396. doi:10.11 36/bjsports-2018-099836

13. Davenport MH, McCurdy AP, Mottola MF, et al. Impact of prenatal exercise on both prenatal and postnatal anxiety and depressive symptoms: a systematic review and meta-analysis. Br J Sports Med. 2018a;52(21):1376-1385. doi:10.1136/bjsports-2018-099697

14. Davenport MH, Marchand AA, Mottola MF, et al. Exercise for the prevention and treatment of low back, pelvic girdle and lumbopelvic pain during pregnancy: a systematic review and meta-analysis. $\mathrm{Br} J$ Sports Med. 2019;53(2):90-98. doi:10.1136/bjsports-2018-099400

15. Takami M, Tsuchida A, Takamori A, Aoki S, Ito M. Effects of physical activity during pregnancy on preterm delivery and mode of delivery: the Japan Environment and Children's Study, birth cohort study. PLoS One. 2018;13(10):e02066160. doi:10.1371/journal.pone.0206160

16. Rajabi A, Maharlouei N, Rezaianzadeh A, et al. Physical activities (exercises or choreses) during pregnancy and mode of delivery in nulliparous women: a prospective cohort study. Taiwan J Obstet Gynecol. 2018;57(10):18-22. doi:10.1016/j.tjog.2017.12.003

17. American College of Obstetricians and Gynaecologists. Physical activity and exercise during pregnancy and the postpartum period. Committee opinion No. 804. Obstet Gynecol. 2017;126:e135-e142.

18. Baker JH, Rothenberger SD, Kline CE, Okun ML. Exercise during early pregnancy is associated with greater sleep continuity. Behav Sleep Med. 2018;16(5):482-493. doi:10.1080/15402002.2016.1228649

19. Barakat R, Pelaez M, Lopez C, Montejo R, Coteron J. Exercise during pregnancy reduces the rate of caesarean and instrumental deliveries: results of a randomized controlled trial. J Matern Fetal Neonat Med. 2012;25(11):2372-2376. doi:10.3109/14767058.2012.696165

20. Cid M, González M. Potential benefits of physical activity during pregnancy for the reduction of gestational diabetes prevalence and oxidative stress. Early Hum Dev. 2016;94:57-62. doi:10.1016/j. earlhumdev.2016.01.007

21. Vargas-terrones M, Barakat R, Santacruz B, et al. Physical exercise programme during pregnancy decreases perinatal depression risk: a randomised controlled trial. Br J Sports Med. 2018;53(6):348-353. doi:10.1136/bjsports-2017-098926

22. Szegda K, Bertone-Johnson ER, Pekow P, et al. Physical activity and depressive symptoms during pregnancy among Latina women: a prospective cohort study. BMC Preg Childbirth. 2018;18:252-263. doi:10.1186/s12884-018-1839-5

23. Padmapriya N, Shen L, Soh SE, et al. Physical activity and sedentary behavior patterns before and during pregnancy in a multi-ethnic sample of Asian women in Singapore. Matern Child Health J. 2015;19(11):2523-2535. doi:10.1007/s10995-015-1773-3

24. Patrícia V, De Sousa S, Cury A, Eufrásio LS. The influence of gestational trimester, physical activity practice and weight gain on the low back and pelvic pain intensity in low risk pregnant women. $J$ Back Musculoskelet Rehabil. 2019;32(5):671-676. doi:10.3233/ BMR-171006

25. Nguyen PTH, Binns CW, Nguyen CL, et al. Physical activity during pregnancy is associated with improved breastfeeding outcomes: a prospective cohort study. Int J Environ Res Public Health. 2019;16 (10):1740. doi:10.3390/ijerph16101740
26. American College of Obstetricians and Gynaecologists. Physical activity and exercise during pregnancy and the postpartum period. Committee opinion No. 804. Obstet Gynecol. 2020;135:e178-e188. doi:10.1097/AOG.0000000000003772

27. Tinius RA, Cahill AG, Cade WT. Origins in the womb: potential role of the physical therapist in modulating the deleterious effects of obesity on maternal and offspring health through movement promotion and prescription during pregnancy. Phys Ther. 2017;97(1):114123. doi: $10.2522 / \mathrm{ptj} .20150678$

28. Tinius R, Nagpal TS, Edens K, et al. Exploring beliefs about exercise among pregnant women in rural communities. J Midwifery Womens Health. 2020;65(4):538-545. doi:10.1111/jmwh.13080

29. Guelfi KJ, Wang C, Dimmock JA, et al. A comparison of beliefs about exercise during pregnancy between Chinese and Australian pregnant women. BMC Preg Childbirth. 2015;15:345. doi:10.1186/ s12884-015-0734-6

30. Findley A, Smith DM, Hesketh K, Keyworth C. Exploring women's experiences and decision making about physical activity during pregnancy and following birth: a qualitative study. BMC Preg Childbirth. 2020;20:54. doi:10.1186/s12884-019-2707-7

31. Mbada CE, Adebayo OE, Adeyemi AB, et al. Knowledge and attitude of Nigerian pregnant women towards antenatal exercise: a cross sectional survey. Obstet Gynecol. 2014;1:8. doi:10.1155/2014/260539

32. Watson ED, Norris SA, Draper CE, et al. "Just because you're pregnant, doesn't mean you're sick!" A qualitative study of beliefs regarding physical activity in black South African women. BMC Preg Childbirth. 2016;16:174. doi:10.1186/s12884-016-0963-3

33. Eastern Cape Socio Economic Consultative Council. Buffalo city metro municipality socio economic review and outlook. 2020. Available online: https://www.ecsecc.org/documentrepository/informationcentre/buffalocity-metro-municipality_44557.pdf. Accessed September 14, 2020.

34. Sarmah HK, Hazarika BB, Choudhury G. An investigation on effect of bais on determination of sample size on the basis of data related to the students of schools of Guwahati. Int J Appl Math Stat Sci. 2013;2:33-48.

35. Evenson KR, Bradley CB. Beliefs about exercise and physical activity among pregnant women. Patient Educ Couns. 2010;79(1):124129. doi:10.1016/j.pec.2009.07.028

36. Da Costa D, Ireland K. Perceived benefits and barriers to leisure-time physical activity during pregnancy in previously inactive and active women. Women Health. 2013;53(2):185-202. doi:10.1080/ 03630242.2012 .758219

37. Hurst C, Flannery C, Byrne M, et al. Investigating the perceived benefits, barriers and beliefs towards physical activity in pregnancy among women with gestational diabetes mellitus. Ir Med J. 2017;110(7):617.

38. Leiferman J, Swibas T, Koiness K, et al. My baby, my move: examination of perceived barriers and motivating factors related to antenatal physical activity. J Midwifery Women's Health. 2011;56 (1):33-40. doi:10.1111/j.1542-2011.2010.00004.x

39. Battle CL, Scott BLD, Fritzson AE, et al. Acceptability and perceived benefits of exercise among pregnant and postpartum women seeking psychiatric care. Women's Health Rep. 2020;1(1):212-217. doi:10.10 89/whr.2020.0039

40. Hoodbhoy Z, Qureshi RN, Iqbal R, Muhabat Q.Household chores as the main source of physical activity: perspectives of pregnant Pakistani women. J Pak Med Assoc. 2018;68(4):565-569.

41. Marquez DX, Bustamante EE, Bock BC, et al. Perspectives of Latina and non-Latina white women on barriers and facilitators to exercise in pregnancy. Women Health. 2009;49(6):505-521. doi:10.1080/ 03630240903427114

42. Pathirathna ML, Sekijima K, Sadakata M, et al. Effects of physical activity during pregnancy on neonatal birth weight. Sci Rep. 2019;9 (1):6000. doi:10.1038/s41598-019-42473-7

43. Henriksson P, Sandborg J, Blomberg M, et al. A smartphone app to promote healthy weight gain, diet, and physical activity during pregnancy (HealthyMoms): protocol for a randomized controlled trial. JMIR Res Protoc. 2019;8(3):e13011. doi:10.2196/13011 
44. O’Brien OA, McCarthy M, Gibney ER, McAuliffe FM. Technology supported dietary and lifestyle interventions in healthy pregnant women: a systematic review. Eur J Clin Nutr. 2014;68(7):760-766. doi:10.1038/ejen.2014.59

45. Hussain T, Smith P, Yee LM. Mobile phone-based behavioral interventions in pregnancy to promote maternal and fetal health in highincome countries: systematic review. JMIR mHealth uHealth. 2020;8 (5):e15111. doi:10.2196/15111

46. Krans EE, Gearhart JG, Dubbert PM, et al. Pregnant women's beliefs and influences regarding exercise during pregnancy. J Miss State Med Assoc. 2005;46(3):67-73.

47. Al-Youbi GM, Elsaid T. Knowledge, attitude, and practices on exercise among pregnant females attending Al-Wazarat Health Center, Riyadh, Saudi Arabia. J Fam Med Prim Care. 2020;9:3905-3915. doi:10.4103/jfmpc.jfmpc_276_20

48. Hayes L, Mcparlin C, Kinnunen T, et al. Change in level of physical activity during pregnancy in obese women: findings from the UPBEAT pilot trial. BMC Preg Childbirth. 2015;15:52. doi:10.11 86/s12884-015-0479-2

49. Schmidt T, Heilmann T, Savelsberg L, et al. Physical exercise during pregnancy - how active are pregnant women in Germany and how well informed? Geburtshilfe Frauenheilkd. 2017;77(5):508-515 doi:10.1055/s-0043-107785

50. Bauer C, Graf C, Platschek AM, et al. Reasons, motivational factors, and perceived personal barriers to engagement in physical activity during pregnancy vary within the BMI classes: the prenatal prevention project Germany. $J$ Phys Act Health. 2018;15(3):204-211. doi:10.1123/jpah.2016-0563

51. Di Fabio DR, Blomme CK, Smith KM, et al. Adherence to physical activity guidelines in mid-pregnancy does not reduce sedentary time: an observational study. Int J Behav Nutr Phys Act. 2015;12:27. doi:10.1186/s12966-015-0191-7

52. Lawan A, Awotidebe AW, Oyeyemi AL, et al. Relationship between physical activity and health related quality of life among pregnant women. Afr J Reprod Health. 2018;22(3):80-89. doi:10.29063/ ajrh2018/v22i3.9

53. Watson ED, van Poppel MNM, Jones RA, et al. Are South African mothers moving? Patterns and correlates of physical activity and sedentary behavior in pregnant black South African women. $J$ Phys Act Health. 2017;14(5):329-335. doi:10.1123/jpah.2016-0388

54. Todorovic J, Terzic-Supic Z, Bjegovic-Mikanovic V, et al. Factors associated with the leisure-time physical activity (LTPA) during the first trimester of the pregnancy: the cross-sectional study among pregnant women in Serbia. Int $J$ Environ Res Public Health. 2020;17(4):1366. doi:10.3390/ijerph17041366

55. Hailemariam TT, Gebregiorgis YS, Gebremeskel BF, et al. Physical activity and associated factors among pregnant women in Ethiopia: facility-based cross-sectional study. BMC Pregnancy Childbirth. 2020;20:92. doi:10.1186/s12884-020-2777-6

56. Harrison AL, Taylor NF, Shields N, et al. Attitudes, barriers and enablers to physical activity in pregnant women: a systematic review. J Physiother. 2018;64(1):24-32. doi:10.1016/j.jphys.2017.11.012

57. Ajzen I. The theory of planned behavior. Organ Behav Hum Decis Process. 1991;50(2):179-211. doi:10.1016/0749-5978(91)90020-T

58. Armitage CJ, Conner M. Efficacy of the theory of planned behavior: a meta-analytic review. $B r \quad J$ Soc Psychol. 2001;40:471-499. doi:10.1348/014466601164939

59. Bozionelos G, Bennett P. The theory of planned behavior as predictor of exercise: the moderating influence of beliefs and personality variables. J Health Psychol. 1999;4(4):517-529. doi:10.1348/014466 601164939

60. Walker RE, Choi TST, Quong S, et al. "It's not easy" - A qualitative study of lifestyle change during pregnancy. Women Birth. 2020;33(4): e363-e370. doi:10.1016/j.wombi.2019.09.003
61. Willcox JC, Campbell KJ, McCarthy EA, et al. Gestational weight gain information: seeking and sources among pregnant women. $B M C$ Preg Childbirth. 2015;15:164. doi:10.1186/s12884-015-0600-6

62. Dalhaug EM, Haakstad LAH. What the health? Information sources and maternal lifestyle behaviors. Interact J Med Res. 2019;8(3): e10355. doi:10.2196/10355

63. Mercado A, Marquez B, Abrams B, et al. Where do women get advice about weight, eating, and physical activity during pregnancy? J Womens Health. 2017;26(9):951-956. doi:10.1089/jwh.2016.6078

64. Flannery C, McHugh S, Anaba AE, et al. Enablers and barriers to physical activity in overweight and obese pregnant women: an analysis informed by the theoretical domains framework and COM-B model. BMC Pregnancy Childbirth. 2018;18(1):178. doi:10.1186/ s12884-018-1816-z

65. Hayman M, Reaburn P, Alley S, et al. What exercise advice are women receiving from their healthcare practitioners during pregnancy? Women Birth. 2020;33(4):e357-e362. doi:10.1016/j.wombi. 2019.07.302

66. De Vivo M, Mills H. "They turn to you first for everything”: insights into midwives' perspectives of providing physical activity advice and guidance to pregnant women. BMC Preg Childbirth. 2019;19:462. doi:10.1186/s12884-019-2607-x

67. Muzigaba M, Kolbe-Alexander TL, Wong F. The perceived role and influencers of physical activity among pregnant women from low socioeconomic status communities in South Africa. J Phy Act Health. 2014;11(7):1276. doi:10.1123/jpah

68. Watson ED, Oddie B, Constantinou D. Exercise during pregnancy: knowledge and beliefs of medical practitioners in South Africa: a survey study. BMC Preg Childbirth. 2015;15:245. doi:10.1186/ s12884-015-0690-1

69. Ferrari RM, Siega-Riz AM, Evenson KR, et al. A qualitative study of women's perceptions of provider advice about diet and physical activity during pregnancy. Patient Educ Couns. 2013;91(3):372377. doi:10.1016/j.pec.2013.01.011

70. Grenier LN, Atkinson SA, Mottola MF, et al. Be healthy in pregnancy: exploring factors that impact pregnant women's nutrition and exercise behaviors. Matern Child Nutr. 2020:e13068. doi:10.1111/ men. 13068

71. Narasimhulu DM, Karakash S, Weedon J, et al. Patterns of internet use by pregnant women, and reliability of pregnancy-related searches. Matern Child Health J. 2016;20(12):2502-2509. doi:10. 1007/s10995-016-2075-0

72. Huberty J, Dinkel D, Beets MW, et al. Describing the use of the internet for health, physical activity, and nutrition information in pregnant women. Matern Child Health J. 2013;17(8):1363-1372. doi:10.1007/s10995-012-1160-2

73. Gao L, Larsson M, Lou S. Internet use by Chinese women seeking pregnancy-related information. Midwifery. 2013;29:730-735. doi:10. 1016/j.midw.2012.07.003

74. Sayakhot P, Carolan-Olah M. Internet use by pregnant women seeking pregnancy-related information: a systematic review. $B M C$ Pregnancy Childbirth. 2016;16:65. doi:10.1186/s12884-016-0856-5

75. Coll CVN, Domingues MR, Gonçalves H, et al. Perceived barriers to leisure-time physical activity during pregnancy: a literature review of quantitative and qualitative evidence. J Sci Med Sport. 2017;20 (1):17-25. doi:10.1016/j.jsams.2016.06.007

76. Girard AW, Olude O. Nutrition education and counselling provided during pregnancy: effects on maternal, neonatal and child health outcomes. Paediatr Perinat Epidemiol. 2012;26(Suppl. 1):191-204. doi:10.1111/j.1365-3016.2012.01278.x 


\section{Publish your work in this journal}

The Journal of Multidisciplinary Healthcare is an international, peerreviewed open-access journal that aims to represent and publish research in healthcare areas delivered by practitioners of different disciplines. This includes studies and reviews conducted by multidisciplinary teams as well as research which evaluates the results or conduct of such teams or healthcare processes in general. The journal covers a very wide range of areas and welcomes submissions from practitioners at all levels, from all over the world. The manuscrip management system is completely online and includes a very quick and fair peer-review system. Visit http://www.dovepress.com/testimonials. php to read real quotes from published authors. 